\title{
Increased Expression of Angiotensin II Type 2 Receptors in the Solitary-Vagal Complex Blunts Renovascular Hypertension
}

\author{
Graziela Torres Blanch, André Henrique Freiria-Oliveira, Guilherme Fleury Fina Speretta, \\ Eduardo J. Carrera, Hongwei Li, Robert C. Speth, Eduardo Colombari, Colin Sumners,* \\ Débora S.A. Colombari*
}

\begin{abstract}
Angiotensin II increases and decreases arterial pressure by acting at angiotensin type 1 and type 2 receptors, respectively. Renovascular hypertensive rats exhibit a high level of activity of the peripheral and central renin-angiotensin system. Therefore, in the present study, we evaluated the effect of increasing the expression of angiotensin type 2 receptors in the solitary-vagal complex (nucleus of the solitary tract/dorsal motor nucleus of the vagus), a key brain stem region for cardiovascular regulation, on the development of renovascular hypertension. Holtzman normotensive rats were implanted with a silver clip around the left renal artery to induce 2-kidney 1-clip renovascular hypertension. Three weeks later, rats were microinjected in the solitary-vagal complex with either an adenoassociated virus to increase the expression of angiotensin type 2 receptors or with a control vector. We observed that increasing angiotensin type 2 receptor expression in the solitary-vagal complex attenuated the development of renovascular hypertension and also reversed the impairment of the baroreflex and the increase in the low-frequency component of systolic blood pressure observed in renovascular hypertensive rats. Furthermore, an observed decrease in mRNA levels of angiotensin-converting enzyme 2 in the solitary-vagal complex of renovascular hypertensive rats was restored to control levels after viral-mediated increases in angiotensin type 2 receptors at this site. Collectively, these data demonstrate specific and beneficial effects of angiotensin type 2 receptors via the brain of hypertensive rats and suggest that central angiotensin type 2 receptors may be a potential target for therapeutics in renovascular hypertension. (Hypertension. 2014;64:777-783.) • Online Data Supplement
\end{abstract}

Key Words: angiotensin II $\boldsymbol{\square}$ angiotensin-converting enzyme $2 \boldsymbol{\square}$ angiotensin receptor blockers $\boldsymbol{\square}$ baroreflex

$\mathrm{R}^{\mathrm{c}}$ enovascular hypertension, elicited by $\geq 50 \%$ renal artery stenosis or occlusion, affects $\approx 6 \%$ to $8 \%$ of the hypertensive population, especially the eldery. ${ }^{1}$ Although an increase in renin-angiotensin system (RAS) activity plays a pivotal role in the raised blood pressure observed in the early phase of renovascular hypertension, patients with renal vascular hypertension also exhibit sympathoexcitation, which contributes to the pathogenesis of renovascular hypertension. ${ }^{2,3}$ Animal models of renovascular hypertension were demonstrated $\approx 80$ years ago using the Goldblatt 2-kidney 1-clip (2K1C). ${ }^{4}$ These animals also display impaired baroreflexes, ${ }^{5-7}$ an increase in sympathetic nerve activity (SNA), ${ }^{7,8}$ and an overactivity of the RAS. ${ }^{9,10}$ Considering the impairment of the baroreflex and overactivity of the sympathetic nervous system seen in renovascular hypertension, the role of the central nervous system in the development and maintenance of renovascular hypertension has also been demonstrated..$^{8,11}$

There is great interest in understanding the mechanisms underlying the changes in SNA and baroreflexes and for developing therapeutic strategies that will lower blood pressure in hypertensive individuals and animal models of neurogenic hypertension. A major contributor to the changes SNA and baroreflexes is the peptide angiotensin II (Ang II) acting via its neuronal type 1 receptors (AT1R) in cardiovascular control centers in the brain stem and forebrain. ${ }^{12,13}$ Specifically, in the brain stem Ang II acting at AT1R in the nucleus of the solitary tract (NTS) blunts the baroreflex. ${ }^{12,14}$ Because Ang II injection into the NTS also spreads in the dorsal motor nucleus of vagus (DMV), the effects of Ang II in blunting baroreflexes may also involve the DMV. ${ }^{14}$ It is also important to point out

Received January 14, 2014; first decision February 4, 2014; revision accepted May 29, 2014.

From the Department of Physiology and Pathology, School of Dentistry, São Paulo State University, Araraquara, São Paulo, Brazil (G.T.B., A.H.F.-O., G.F.F.S., E.C., D.S.A.C.); Department of Pharmaceutical Sciences, College of Pharmacy, Nova Southeastern University, Fort Lauderdale, FL (E.J.C., R.C.S.); School of Biotechnology, Southern Medical University, Guangzhou, China (H.L.); and Department of Physiology and Functional Genomics and McKnight Brain Institute, College of Medicine, University of Florida, Gainesville (C.S., R.C.S.).

*These authors are co-senior authors.

The online-only Data Supplement is available with this article at http://hyper.ahajournals.org/lookup/suppl/doi:10.1161/HYPERTENSIONAHA. 114.03188/-/DC1.

Correspondence to Débora Simões Almeida Colombari, Departamento de Fisiologia e Patologia, Faculdade de Odontologia de Araraquara-UNESP, Rua Humaitá, 1680, Araraquara, 14801-903, São Paulo, Brazil. E-mail deborac@ foar.unesp.br or Colin Sumners, Department of Physiology and Functional Genomics, College of Medicine, University of Florida, 1600 Southwest Archer Rd, PO Box 100274, Gainesville, FL 32610. E-mail csumners@ufl.edu

(C) 2014 American Heart Association, Inc. 
that, in addition to being the first synaptic relay station in the central nervous system for baroreflex regulation, the NTS plays a part in mediating the high blood pressure and sympathoexcitation seen in spontaneously hypertensive rats. ${ }^{15,16}$ Thus, a potential imbalance between Ang II and constituents of the RAS in the solitary-vagal complex may be involved in the development and maintenance of hypertension, including in the 2K1C Goldblatt model. In fact, we recently demonstrated that NTS overexpression of macrophage migration inhibitory factor, a protein that inhibits the intracellular actions of the AT1R, decreases arterial pressure in spontaneously hypertensive rats. ${ }^{16}$ Thus, mechanisms that seem to oppose the actions of Ang II via AT1R may lead to the development of new antihypertensive therapies for people with uncontrolled high blood pressure.

A potential opposing or protective mechanism is the action of Ang II via its type 2 receptors (AT2R). There is evidence that the activation of AT2R can oppose the actions of Ang II via AT1R in the cardiovascular system. ${ }^{17}$ AT2R knockout mice exhibit elevated basal blood pressure and a greater sensitivity to the vasopressor effect of Ang II. ${ }^{18,19}$ In addition, coadministration of an AT2R agonist (compound 21) with the AT1R antagonist candesartan induced a greater fall in arterial pressure in spontaneously hypertensive rats when compared with candesartan alone in these animals. ${ }^{20}$ Besides these peripheral effects, in vitro studies using cocultures of hypothalamus and brain stem cells demonstrated that AT2R activation stimulates the delayed rectifier $\mathrm{K}^{+}$current, decreasing the excitability of the cells, whereas AT1R activation exerts an opposite effect. ${ }^{21}$

Thus, considering that AT2R and AT1R activation exert opposite effects, and the importance of solitary/vagal complex to the regulation of arterial pressure and baroreflex, ${ }^{22}$ we investigated whether long-term increased expression of AT2R in the solitary vagal complex (NTS/DMV) of $2 \mathrm{~K} 1 \mathrm{C}$ rats would affect the development/maintenance of renovascular hypertension. Furthermore, we investigated alterations in the expression of various RAS genes (AT1R, AT2R, and angiotensin-converting enzyme 2 [ACE2]) at the solitary-vagal complex as a potential mechanism for effects of increased AT2R expression on blood pressure. We were particularly interested in ACE2 because it is known that the ACE2/angiotensin-(1-7)/Mas receptor axis is a cardioprotective arm of the RAS, ${ }^{23}$ and chronic activation of AT2R in peripheral tissues activates ACE2. ${ }^{24}$ In addition, overexpression of the human form of this enzyme in the paraventricular nucleus of hypothalamus impaired the development of Ang II-induced hypertension, ${ }^{25}$ and the increase in SNA observed in mice with chronic heart failure was reduced in transgenic mice with overexpression of human ACE2 in the NTS and rostral ventrolateral medulla (RVLM). ${ }^{26}$

\section{Methods}

Detailed descriptions of the animal subjects and all experimental methods are included in the online-only Data Supplement. Given below are the experimental protocols used.

\section{Experiment 1}

Two months after adeno-associated virus serotype 2(AAV2)-chicken $\beta$-actin promoter (CBA)-AT2R or AAV2-CBA-enhanced green fluorescent protein (eGFP) were injected into the NTS/DMV of naïve male Sprague-Dawley rats $(n=3)$, animals were deeply anesthetized, perfused transcardially, and the brain stem was processed for AT2R autoradiography as described in the online-only Data Supplement.

\section{Experiment 2}

Male Holtzman rats ( $n=5-6$ per group) underwent $2 \mathrm{~K} 1 \mathrm{C}$ surgery and implantation of telemetry transducers, and 21 days later animals received microinjections of either AAV2-CBA-eGFP or AAV2-CBAAT2R into the NTS/DMV. Mean arterial pressure (MAP) and heart rate were recorded continuously, for a 24-hour period, 18 and 3 days before vector injection, and 7, 14, 21, 26, and 31 days after vector injection. Rats were euthanized at 31 days after vector injection, brain stems were removed, cut, and mounted on slides to check the eGFP fluorescence in the NTS/DMV and to indicate NTS/DMV injection site.

\section{Experiment 3}

Male Holtzman rats ( $\mathrm{n}=8-9$ per group) underwent sham or $2 \mathrm{~K} 1 \mathrm{C}$ surgery. This was followed, 21 to 24 days later, by microinjections of either AAV2-CBA-eGFP or AAV2-CBA-AT2R into the NTS/DMV. In $2 \mathrm{~K} 1 \mathrm{C}$ rats, the systolic arterial pressure was monitored for 3 weeks by tail cuff starting 1 week after the surgery. Only animals with an increase in systolic arterial pressure after 3 weeks of the $2 \mathrm{~K} 1 \mathrm{C}$ surgery underwent virus injection in the NTS/DMV. We will refer to Holtzman rats with sham $2 \mathrm{~K} 1 \mathrm{C}$ surgery as normotensive rats. Four weeks after the viral transduction, rats were implanted with 2 catheters: one into the abdominal aorta through the femoral artery for direct recordings of MAP and heart rate and another into the femoral vein for drug administration. The next day, MAP and heart rate were recorded in conscious rats, followed by the analysis of baroreflex function as described in the Methods in the online-only Data Supplement. The day after these tests, rats were deeply anesthetized, decapitated, and the brains were collected for quantitative reverse transcription polymerase chain reaction analyses of AT1R, AT2R, and ACE2 mRNAs in the NTS/DMV, and the kidneys were weighed.

\section{Results}

\section{Viral-Mediated Expression of GFP and AT2R in the NTS/DMV}

AT2R autoradiography was performed as described in experiment 1 to verify the effectiveness of AAV2-CBA-AT2R in inducing increased AT2R expression in the NTS/DMV. As shown in the representative autoradiograms in Figure 1A to $1 \mathrm{D}$, there is intense AT2R-specific binding in the NTS/DMV of an AAV2-CBA-AT2R-injected rat (Figure 1A) when compared with the NTS/DMV of an AAV2-CBA-eGFPinjected rat (Figure 1B). Figure $1 \mathrm{C}$ and $1 \mathrm{D}$ shows similar levels of AT1R-specific binding in the NTS/DMV of AAV2CBA-AT2R-injected and AAV2-CBA-eGFP-injected rats, respectively. Quantification of the autoradiographic data demonstrated that in the eGFP-transduced rats, AT2R levels are lower in the NTS/DMV when compared with the inferior olivary nucleus but significantly increase only in the NTS/DMV after AT2R transduction $(F(2,6)=46.89 ; P<0.01$; Figure $1 \mathrm{E})$. AT2R transduction in the NTS/DMV did not change AT1R levels at this site (Figure 1E). The representative fluorescence micrographs presented in Figure 1F show eGFP expression at 3 rostro-caudal levels of the solitary-vagal complex, from bregma, 31 days after microinjection of AAV2-CBA-eGFP as described in experiments 2 and 3. Quantitative reverse transcription polymerase chain reaction analyses, after microinjections of either AAV2-CBA-eGFP or AAV2-CBA-AT2R into the NTS/DMV as described in experiment 3, showed that the AT2R vector was effective in increasing AT2R levels in the NTS/DMV (Figure 4A). 

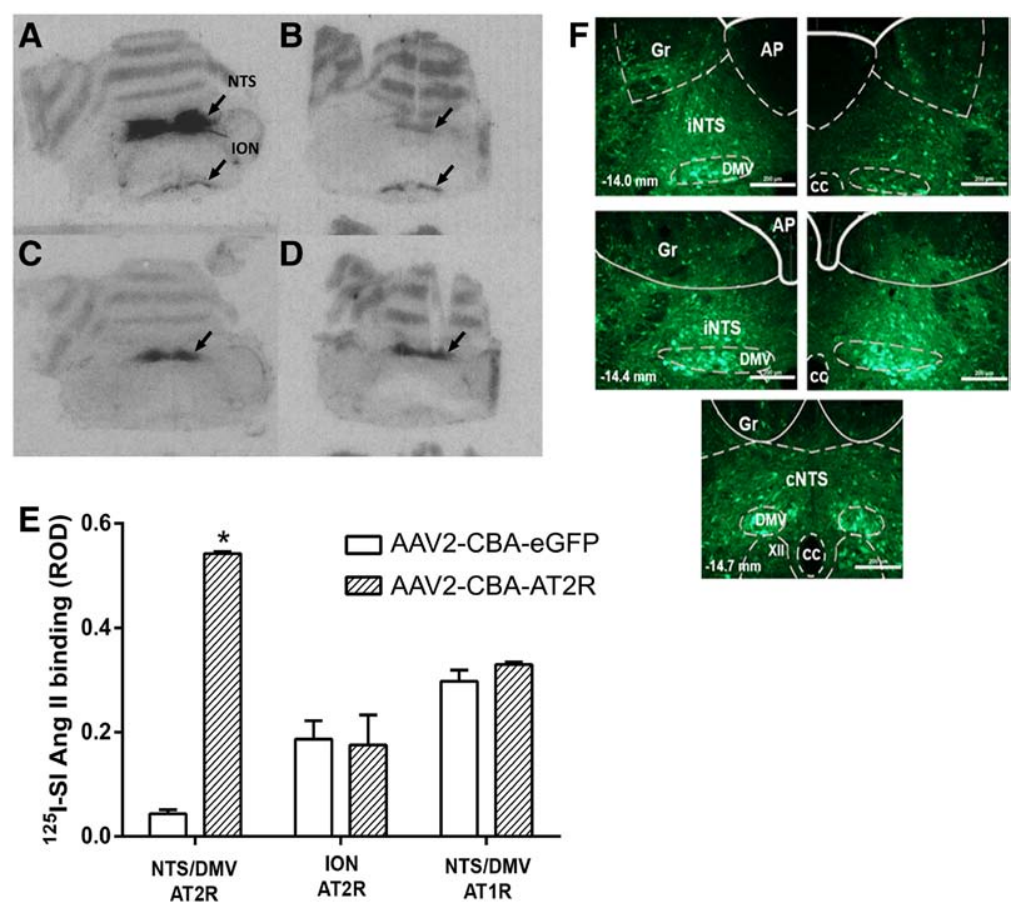

\section{Increasing AT2R Expression in the NTS/DMV} Attenuates the Development of 2K1C Hypertension

The effects of increasing AT2R expression in the NTS were studied as described in the Methods, Experiment 2 section tor injections) were similar in rats assigned to the AT2R or eGFP groups during the light (AT2R, 101 \pm 2 and eGFP, 103 \pm 5 $\mathrm{mm} \mathrm{Hg}$ ) and dark periods (AT2R, 112 \pm 4 and eGFP, $111 \pm 5$ $\mathrm{mm} \mathrm{Hg}$ ). At 3 days before vector injections (21 days after $2 \mathrm{~K} 1 \mathrm{C}$ surgery), rats assigned to the AT2R and eGFP groups exhibited an increase in their MAP when compared with of this article. Baseline levels of MAP (18 days before vec-
Figure 1. Viral-mediated transduction of enhanced green fluorescent protein (eGFP) and angiotensin II type 2 receptor (AT2R) into the brain stem.

A-D, Receptor autoradiography of rat brain stem using ${ }^{125}$-SI-angiotensin II after microinjection of adeno-associated virus serotype 2 (AAV2)-chicken $\beta$-actin promoter (CBA)-eGFP or AAV2-CBA-AT2R as described in the Methods in the online-only Data Supplement. A, Binding to the AT2R in a representative AT2R-transduced brain. B, Binding to the AT2R in a representative eGFP-transduced (control) brain. C, Binding to the AT1R in a representative AT2R-transduced brain. D, Binding to the AT1R in a representative eGFP-transduced (control) brain. E, Quantification of AT2R density in the nucleus of the solitary tract (NTS)/dorsal motor nucleus of vagus (DMV) and inferior olivary nucleus (ION) and AT1R density in the NTS/DMV of AT2R or eGFP-transduced rats. Data are mean+SEM; $n=3$ per group; ${ }^{\star} P<0.05$ vs corresponding eGFP group. F, Representative fluorescence micrographs taken from coronal sections of the NTS/DMV $(-14.0$ to $-14.7 \mathrm{~mm}$ from bregma) from rats that had received microinjections of AAV2-CBA-eGFP as described in the Methods in the online-only Data Supplement. Scale bar, $200 \mu \mathrm{m}$. AP indicates area postrema; cc, central canal; cNTS, commissural nucleus of the solitary tract; Gr, gracile nucleus; iNTSi, intermediate nucleus of the solitary tract; ROD, relative optical density; and XII, hypoglossal nucleus. baseline levels in the light period (AT2R, 134 \pm 3 and eGFP, $130 \pm 9 \mathrm{mmHg}$ versus respective baselines; $F(1,63)=7.912$; $P<0.05$ ) and in the dark period (AT2R, 133 \pm 3.7 and eGFP, $132 \pm 7 \mathrm{~mm} \mathrm{Hg}$ versus respective baselines; $F(1,63)=52.969$; $P<0.001$; Figure 2A and 2B). In 2K1C-AT2R rats, the development of hypertension was potently attenuated when compared with the $2 \mathrm{~K} 1 \mathrm{C}$-eGFP animals during both light (2K1CAT2R, $154 \pm 7$ versus $2 \mathrm{~K} 1 \mathrm{C}-\mathrm{eGFP}, 179 \pm 11 \mathrm{~mm} \mathrm{Hg}$ at day 31 ; $P<0.05$ ) and dark periods (2K1C-AT2R, $158 \pm 6$ versus $2 \mathrm{~K} 1 \mathrm{C}$ eGFP, $195 \pm 5 \mathrm{~mm} \mathrm{Hg}$ at day $31 ; P<0.05$; Figure $2 \mathrm{~A}$ and $2 \mathrm{~B}$ ). There were no significant differences in heart rate between
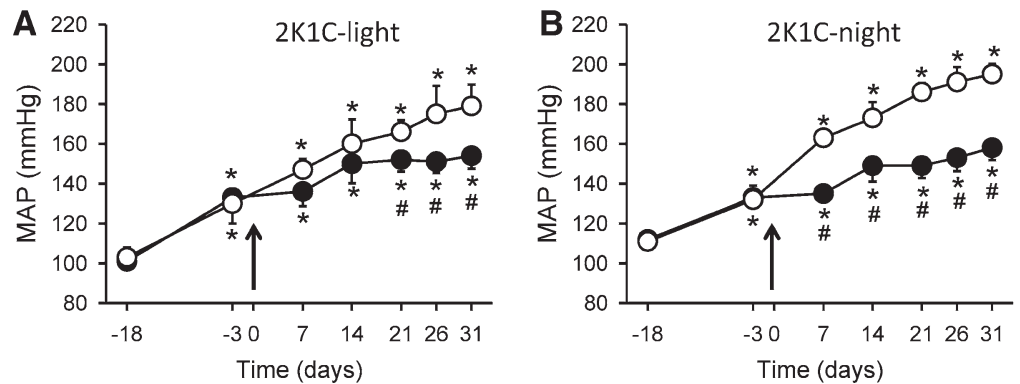

Figure 2. Increased angiotensin II type 2 receptor (AT2R) expression in the nucleus of the solitary tract (NTS)/dorsal motor nucleus of vagus (DMV) decreases the development of hypertension in renovascular hypertensive rats. Shown here are mean arterial pressure (MAP; $\mathrm{mm} \mathrm{Hg}$ ) values from 2-kidney 1-clip (2K1C) rats recorded on the days indicated before and after vector injections (adenoassociated virus serotype 2 [AAV2]-chicken $\beta$-actin promoter [CBA]-enhanced green fluorescent protein [eGFP], open symbols; AAV2-CBA-AT2R, filled symbols) into the NTS/DMV. MAP recordings were made during the light ( $\mathbf{A}$ and $\mathbf{C}$ ) and dark periods ( $\mathbf{B}$ and $\mathbf{D}$ ), and vector injections were made on day 0 (indicated by the arrows). The results are presented as mean $\pm S E M ; n=5$ and 6 rats for the eGFP and AT2R groups, respectively. ${ }^{*} P<0.05$ vs baseline (day -18); $\# P<0.05$ vs eGFP. HR indicates heart rate.

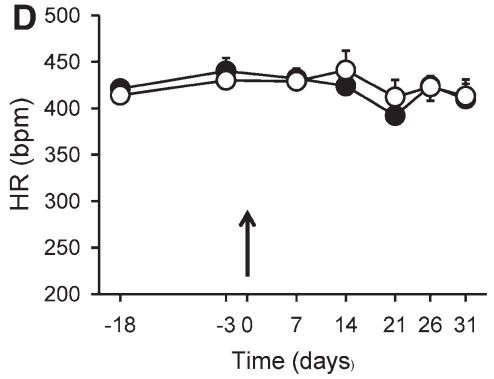



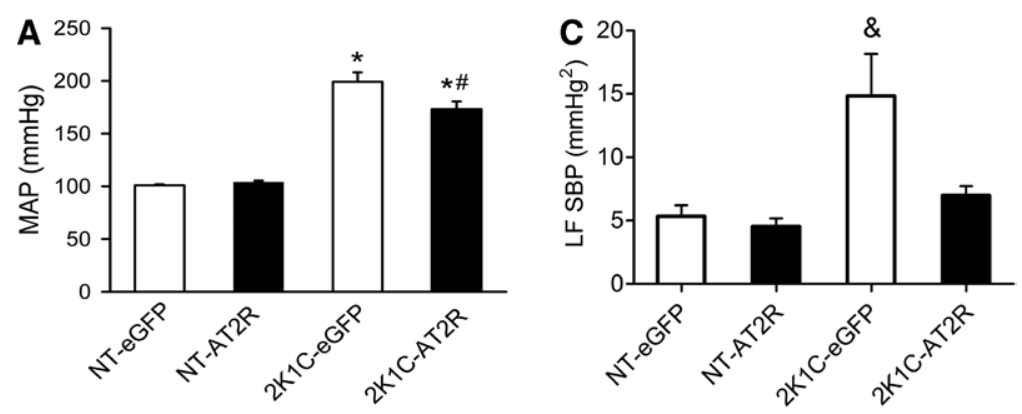

Figure 3. Increased angiotensin II type 2 receptor (AT2R) expression in the solitary tract (NTS)/dorsal motor nucleus of vagus (DMV) restores baroreflex function and decreases the higher low frequency (LF) of systolic blood pressure (SBP) in 2-kidney 1 -clip $(2 \mathrm{~K} 1 \mathrm{C})$ rats. Normotensive (NT) or $2 \mathrm{~K} 1 \mathrm{C}$ rats received intra-NTS injections of adeno-associated virus serotype 2 (AAV2)-chicken $\beta$-actin promoter (CBA)-enhanced green fluorescent protein (eGFP) or AAV2-CBA-AT2R followed by the measurement of mean arterial pressure (MAP), analysis of the SBP variability, and baroreflex function as detailed in the Methods in the online-only Data Supplement.

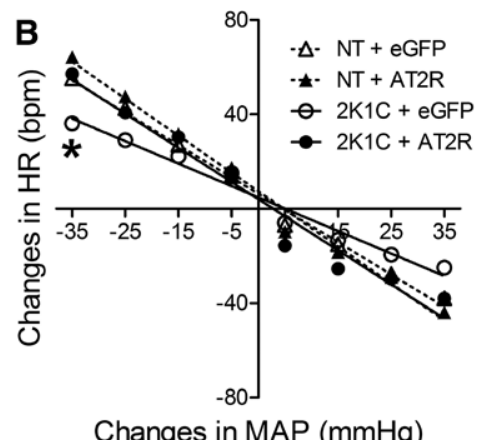
A, Increased AT2R expression in the NTS/DMV decreases mean arterial pressure in $2 \mathrm{~K} 1 \mathrm{C}$ rats but not in normotensive (NT) rats. B, Baroreflex function curves from $2 \mathrm{~K} 1 \mathrm{C}$ and NT rats. Grouped heart rate $(\mathrm{HR})$ baroreflex slopes in response to each 10 $\mathrm{mm} \mathrm{Hg}$ change in MAP produced by phenylephrine (pressor) or sodium nitroprusside (depressor) as described in the Methods in the online-only Data Supplement. C, Power of SBP spectra at the LF band. Results in $\mathbf{A}$ and $\mathbf{C}$ are presented as mean \pm SEM; NT-eGFP, $n=8$; NT-AT2R, $n=9$; 2K1C-eGFP, $n=9$; 2K1C-AT2R, $n=9 .{ }^{*} P<0.05$ vs respective treatment in NT rats; $\# P<0.05$ vs $2 \mathrm{~K} 1 \mathrm{C}$ eGFP; $\& P<0.05$ vs all groups.

the treatment groups either in the light or in the dark periods in $2 \mathrm{~K} 1 \mathrm{C}$ rats $(F(1,63)=0.522 ; P=0.473$ and $F(1,63)=0.0793$; $P=0.779$, respectively; Figure $2 \mathrm{C}$ and $2 \mathrm{D})$.

\section{Baroreflex Impairment and Increased Low Frequency of Systolic Blood Pressure in 2K1C Rats Are Restored After Increasing AT2R Expression in the NTS/DMV}

Baseline MAP levels of the animals that underwent baroreflex tests are shown in Figure 3A. The data indicate that the high levels of baseline MAP that occur in the $2 \mathrm{~K} 1 \mathrm{C}$-eGFP group were significantly reduced in the $2 \mathrm{~K} 1 \mathrm{C}$-AT2R (Figure $3 \mathrm{~A}$; $F(1,31)=64.841 ; P<0.001)$. We also observed that the ratio of the left kidney:right kidney weight in $2 \mathrm{~K} 1 \mathrm{C}$ rats was decreased when compared with that observed in normotensive rats, as demonstrated previously, ${ }^{27}$ and there were no differences between the eGFP- and AT2R-treated groups (Table). In contrast to the $2 \mathrm{~K} 1 \mathrm{C}$ animals, there was no change in MAP after AT2R vector injection into the NTS/DMV in normotensive rats (Figure $3 \mathrm{~A}$ ).

Baroreflexes were assessed using a dose of phenylephrine that elicits a pressor response and a dose of sodium nitroprusside that causes a depressor effect as described in the Methods, Experiment 3 section of this article (online-only Data Supplement). The $2 \mathrm{~K} 1 \mathrm{C}$-eGFP rats displayed an impairment of baroreflex function (2K1C-eGFP slope, $-0.95 \pm 0.05$ versus normotensive-eGFP slope, $-1.37 \pm 0.06 \mathrm{bpm} / \mathrm{mm} \mathrm{Hg}$; $F(3,31)=6.175 ; P<0.05$; Figure $3 \mathrm{~B})$. Importantly, in $2 \mathrm{~K} 1 \mathrm{C}$ AT2R rats, the baroreflex function was restored (slope, $-1.45 \pm 0.07 \mathrm{bmp} / \mathrm{mm} \mathrm{Hg}$ ) to the levels observed in normotensive rats (normotensive-AT2R slope, $-1.56 \pm 0.07$ and normotensive-eGFP slope, $-1.37 \pm 0.06 \mathrm{bpm} / \mathrm{mm} \mathrm{Hg}$; Figure $3 \mathrm{~B}$ ).

Using spectral analysis of systolic blood pressure (SBP), we observed that the low frequency (LF) of SBP, an index of vasomotor sympathetic activity, was significantly higher in the $2 \mathrm{~K} 1 \mathrm{C}$-eGFP-transduced rats $\left(14.8 \pm 3.3 \mathrm{~mm} \mathrm{Hg}^{2}\right)$ but was reduced in $2 \mathrm{~K} 1 \mathrm{C}$-AT2 $\mathrm{R}$ rats $\left(7.0 \pm 0.7 \mathrm{~mm} \mathrm{Hg}^{2}\right)$, returning to values comparable with those seen in normotensive animals (normotensive-eGFP, $5.4 \pm 0.9$ and normotensive-AT2R, $4.5 \pm 0.6 ; F(3,26)=6.613 ; P<0.01$; Figure $3 \mathrm{C})$. LF and high frequency $(\mathrm{HF})$ of pulse interval (PI) were not different among the groups (Figure S1 in the online-only Data Supplement) although there was a tendency for LF of PI to increase and for $\mathrm{HF}$ of PI to decrease in the 2K1C-eGFP group. Indeed, when the $\mathrm{LF} / \mathrm{HF}$ ratio is calculated, a higher ratio was found in $2 \mathrm{~K} 1 \mathrm{C}$-eGFP $(0.23 \pm 0.024$ versus other groups; $P<0.05)$, probably because of a combination of higher LF and decreased HF of PI in these animals (Figure S1)

\section{Reduced ACE 2 mRNA Levels in the NTS/DMV of 2K1C Rats Are Restored in the AAV2-CBA-AT2R- Injected Rats}

As expected, the normotensive-AT2R and 2K1C-AT2R groups displayed a higher level of AT2R mRNA in the NTS when compared with the eGFP-injected rats (normotensive-AT2R, $0.45 \pm 0.13$ and $2 \mathrm{~K} 1 \mathrm{C}-\mathrm{AT} 2 \mathrm{R}, 0.425 \pm 0.9$

Table. LK/RK in 2K1C Rats and NT Rats 31 Days After Transduction With AAV2-CBA-eGFP or AAV2-CBA-AT2R

\begin{tabular}{lllc}
\hline Rat & Treatment & $\mathrm{n}$ & LK/RK \\
\hline NT & AAV2-CBA-eGFP & 9 & $0.97 \pm 0.02$ \\
NT & AAV2-CBA-AT2R & 9 & $0.98 \pm 0.01$ \\
2K1C & AAV2-CBA-eGFP & 6 & $0.61 \pm 0.04^{*}$ \\
2K1C & AAV2-CBA-AT2R & 9 & $0.67 \pm 0.04^{*}$ \\
\hline
\end{tabular}

Increased expression of AT2R in the solitary-vagal complex blunts renovascular hypertension. 2K1C indicates 2-kidney 1-clip; AAV2, adenoassociated virus serotype 2; AT2R, angiotensin II type 2 receptors; CBA, chicken $\beta$-actin promoter; eGFP, enhanced green fluorescent protein; LK/RK, left kidney/ right kidney ratio; $n$, number of animals; and NT, normotensive.

*Different from NT; 1-way ANOVA, followed by Student-Newman-Keuls, $P<0.05$. 


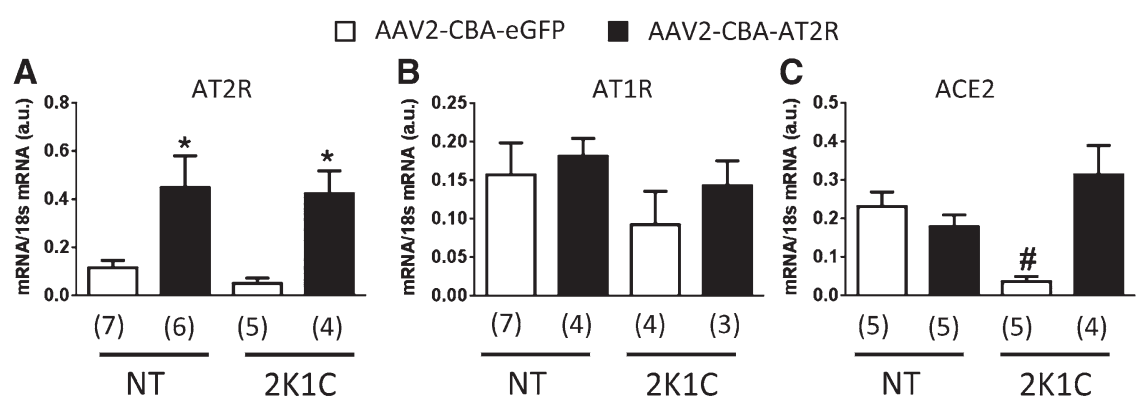

Figure 4. Angiotensin II (Ang II) type 2 receptor (AT2R), AT1R, and angiotensin-converting enzyme 2 (ACE2) mRNA levels in the nucleus of the solitary tract (NTS)/dorsal motor nucleus of vagus (DMV) of 2-kidney 1-clip (2K1C) and normotensive (NT) rats. After euthanization of the rats used in the experiment in Figure 3, brains were removed, and mRNA levels of Ang II receptors and ACE2 in the NTS/DMV were assessed by real-time quantitative reverse transcription polymerase chain reaction. The results are presented as mean $\pm S E M ; n$ is indicated in parentheses; ${ }^{\star} P<0.05$ vs eGFP; $\# P<0.05$ vs all groups. eGFP indicates enhanced green fluorescent protein.

versus normotensive-eGFP, $0.117 \pm 0.03$ and $2 \mathrm{~K} 1 \mathrm{C}-\mathrm{AT} 2 \mathrm{R}$, $0.05 \pm 0.023 ; F(3,18)=6.013 ; P<0.05$; Figure 4A). However, AT2R overexpression did not influence AT1R mRNA levels $(F(3,14)=0.750 ; P>0.05$; Figure $4 \mathrm{~B})$. The $2 \mathrm{~K} 1 \mathrm{C}$-eGFP rats displayed decreased levels of ACE2 mRNA in the NTS/DMV when compared with the normotensive rats $(0.037 \pm 0.014$, versus other groups; $F(3,15)=7.775 ; P<0.05)$. Interestingly, the lower levels of ACE2 mRNA found in 2K1C-eGFP were restored in $2 \mathrm{~K} 1 \mathrm{C}$-AT2R rats to those observed in the normotensive rats $(2 \mathrm{~K} 1 \mathrm{C}-\mathrm{AT} 2 \mathrm{R}, 0.314 \pm 0.076$ versus normotensiveeGFP, $0.232 \pm 0.037$ and normotensive-AT2R, 0.180 \pm 0.0304 ; $P>0.05$; Figure 4C).

\section{Discussion}

The role of the RAS and particularly AT1R in the development and maintenance of renovascular hypertension is well established. ${ }^{9,10,28}$ In addition to the peripheral RAS, higher levels of Ang II and AT1R are present in different brain areas in $2 \mathrm{~K} 1 \mathrm{C}$ hypertensive rats, including in the paraventricular nucleus in the hypothalamus and the RVLM in the brain stem, ${ }^{8,29,30}$ suggesting that the central RAS has a pivotal role in the development/maintenance of hypertension of the $2 \mathrm{~K} 1 \mathrm{C}$ model. In contrast to the established role of central and peripheral AT1R, in renovascular hypertension, to date there have been no studies implicating a role of central AT2R in this form of high blood pressure. In fact, studies from mice suggested that AT2R do not have a counter-regulatory effect against the hypertensive action of Ang II acting via AT1AR in $2 \mathrm{~K} 1 \mathrm{C}$ hypertension. ${ }^{28}$ In contrast, the present study has demonstrated, unequivocally and for the first time, an effect of AT2R in the solitary-vagal complex, a brain stem region that is important in the control of arterial pressure and for the development and maintenance of renovascular hypertension. Our current data demonstrate that increased expression of AT2R in the solitary-vagal complex attenuates the increase in arterial pressure observed in $2 \mathrm{~K} 1 \mathrm{C}$ rats.

In the past decade, studies have begun to shed light on the role of AT2R in cardiovascular control. ${ }^{17}$ Despite low levels of endogenous AT2R in several brain stem areas of adult rats, including the NTS/DMV as demonstrated in the present study and others, ${ }^{31}$ functional data indicate that central AT2R can influence blood pressure. Specifically, chronic intracerebroventricular infusion of the selective AT2R agonist Compound 21 reduced arterial pressure and norepinephrine excretion in normotensive rats, suggesting that SNA has been decreased. ${ }^{32}$ Another study from the same group ${ }^{33}$ demonstrated that adenoviral-mediated increases in the expression of AT2R in the RVLM of normotensive rats elicited a reduction in nocturnal MAP and norepinephrine excretion, and an increase in urine excretion, possibly as a result of sympathoinhibition. This effect of AT2R overexpression on arterial pressures of normotensive rats seems to be specific for the RVLM because in the present study 30 days after AT2R transduction in the NTS/DMV of normotensive rats, there was no change in MAP (Figure 3A).

It is well established that the baroreflex is attenuated in $2 \mathrm{~K} 1 \mathrm{C}$ rats, and impairment of the baroreflex seems to be critical in the development and maintenance of $2 \mathrm{~K} 1 \mathrm{C}$ hyperten$\operatorname{sion}^{5-7}$ because a reduction in the baroreflex gain might also contribute to the increase in sympathetic outflow and high blood pressure. ${ }^{34}$ Evidence suggests that in $2 \mathrm{~K} 1 \mathrm{C}$ rats Ang II acting via its AT1R in the NTS is responsible for dampening the baroreflexes in renovascular hypertension. For example, circulating Ang II levels are high, especially during phase I (first 4 weeks) of 2K1C renovascular hypertension, ${ }^{9,10}$ and Ang II acting at AT1R within the NTS has been reported to attenuate baroreflex function. ${ }^{12,14}$ Similar to the findings in the present study, Oliveira-Sales et $\mathrm{al}^{7}$ demonstrated that during phase I of $2 \mathrm{~K} 1 \mathrm{C}$ hypertension, there is an impairment of the baroreflex, and this may be related to the high levels of Ang II.

The present study demonstrated, in a striking manner, that after increasing AT2R expression in the solitary-vagal complex of $2 \mathrm{~K} 1 \mathrm{C}$ rats, baroreflex function was restored to control levels. The mechanism involved in the restoration of the baroreflex remains to be determined, but it may involve the ACE2/angiotensin-(1-7)/Mas receptor axis based on the following evidence. ACE2 has high catalytic activity to convert Ang II to angiotensin-(1-7), ${ }^{35}$ and this enzyme is present in rat NTS as observed previously ${ }^{36}$ and also in the present study. Angiotensin-(1-7) has been shown to increase baroreflex sensitivity in the NTS, ${ }^{37}$ and overexpression of human ACE2 in the NTS and RVLM of mice enhances baroreflex function. ${ }^{26}$ Conversely, microinjection of an ACE2 inhibitor into the NTS decreased baroreflex sensitivity. ${ }^{38}$ In the present study, we observed a significant decrease in ACE2 mRNA levels in the solitary-vagal complex of $2 \mathrm{~K} 1 \mathrm{C}-\mathrm{eGFP}$ rats but not in the $2 \mathrm{~K} 1 \mathrm{C}$-AT2R animals. Thus, it is possible that in the $2 \mathrm{~K} 1 \mathrm{C}$-eGFP rats, the observed decrease in baroreflex 
sensitivity and altered sympathovagal balance (indicated by the ratio of LF:HF of PI) was because of an imbalance of ACE2 in the solitary-vagal complex. Restoring the levels of ACE2 (and therefore angiotensin-(1-7)) via overexpression of AT2R at the NTS/DMV may have ameliorated the loss of baroreflex function and the altered sympathovagal balance normally seen in $2 \mathrm{~K} 1 \mathrm{C}$ rats, consequently reducing their hypertension. In accordance with this idea, Ali et al ${ }^{24}$ demonstrated that CGP42112A, an AT2R agonist, increase the expression of ACE2 and Mas receptors in the HK-2 cell line. In vivo data, in the same study, demonstrated that the lower expression levels and the activity of ACE2 in obese Zucker rats were restored after 2 weeks treatment with CGP42112A. Therefore, it seems that the activation of AT2R leads to an increase in ACE2 expression, similar to that observed in the present study. However, the molecular mechanisms involved in the regulation of ACE2 mRNA expression in the NTS by AT2R levels are yet to be determined.

In addition to the baroreceptor impairment in $2 \mathrm{~K} 1 \mathrm{C}$ rats, another mechanism that could account for the hypertension in $2 \mathrm{~K} 1 \mathrm{C}$ rats is the increase in SNA observed in these animals. ${ }^{7,8}$ It has been reported that NTS inhibition reduces arterial pressure and SNA in spontaneously hypertensive rats. ${ }^{15}$ Although we have not directly measured SNA, we observed that in $2 \mathrm{~K} 1 \mathrm{C}-\mathrm{eGFP}$, there was an increase in LF of SBP. Because LF of SBP is an index of vasomotor sympathetic activity, it is possible that AT2R overexpression in the NTS/DMV induced a decrease in the sympathoexcitation in $2 \mathrm{~K} 1 \mathrm{C}$ rats. As pointed out earlier in the discussion, MAP did not totally recover to normotensive values after AT2R overexpression in the NTS/DMV. Viral transduction was made between phases I and II (5-8 weeks) of $2 \mathrm{~K} 1 \mathrm{C}$ hypertension. ${ }^{10}$ In phase II, both SNA and MAP are increased by volume retention, decreased sodium excretion, and an increase in Ang II sensitivity. ${ }^{7,9,10}$ all of which might be not directly affected by the AT2R overexpression in the solitary-vagal complex.

In conclusion, the current results indicate that increased expression of AT2R within the NTS/DMV of $2 \mathrm{~K} 1 \mathrm{C}$ rats impairs the full development of hypertension in these animals. The restoration of baroreflex function and an increase of LF of SBP produced by increased AT2R expression are associated with increased ACE2 mRNA levels in the solitary-vagal complex, and this may be an important mechanism that contributed to these responses.

\section{Perspectives}

Despite a variety of treatment regimens hypertension, and in particular high blood pressure associated with enhanced sympathetic outflow, remains a worldwide problem. Although it is well known that sympathoexcitation is involved in renovascular hypertension, the underlying mechanisms including a role for AT2R, and whether they antagonize AT1R actions in central nervous system cardiovascular control centers, are yet to be established. The current study demonstrates that increasing AT2R expression in the solitary-vagal complex exerts a profound attenuation of the development of renovascular hypertension and restores baroreflex function and sympathetic modulation of arterial pressure to normal values in $2 \mathrm{~K} 1 \mathrm{C}$ rats. As such, the present data demonstrate a specific and beneficial effect of AT2R in a central nervous system cardiovascular control center and suggest that AT2R may be a potential target for therapeutics in hypertension that involves enhanced sympathetic outflow/impaired baroreflex function. Whether this beneficial action of AT2R is a specific antagonism of AT1R effects in the NTS/DMV or simply an opposing effect remains to be determined.

\section{Acknowledgments}

We thank Reginaldo C. Queiroz, Silas P. Barbosa, and Silvia Fóglia for expert technical assistance, Silvana A. D. Malavolta and Carla Molina for secretarial assistance, Malaika Jean-Baptiste for graphical assistance, and Adriano P. Oliveira e Ana V. Oliveira for animal care.

\section{Sources of Funding}

This research was supported by Brazilian public funding from the Conselho Nacional de Desenvolvimento Científico e Tecnológico (304918/2011-3 and 473108/2011-9), Fundação de Amparo a Pesquisa do Estado de São Paulo (2011/50770-1 and 2013/50121-9), Programa Nacional de Pós Doutorado/Coordenação de Aperfeiçoamento de Pessoal de Nível Superior (PNPD/CAPES 2748/2010), and National Institutes of Health grant R01 HL076803.

\section{Disclosures}

None.

\section{References}

1. Hansen KJ, Edwards MS, Craven TE, Cherr GS, Jackson SA, Appel RG, Burke GL, Dean RH. Prevalence of renovascular disease in the elderly: a population-based study. J Vasc Surg. 2002;36:443-451.

2. Remuzzi G. Sympathetic overactivity in hypertensive patients with chronic renal disease. N Engl J Med. 1999;340:1360-1361.

3. Johansson M, Elam M, Rundqvist B, Eisenhofer G, Herlitz H, Lambert G, Friberg P. Increased sympathetic nerve activity in renovascular hypertension. Circulation. 1999;99:2537-2542.

4. Goldblatt H, Lynch J, Hanzal RF, Summerville WW. Studies on experimental hypertension: I. The production of persistent elevation of systolic blood pressure by means of renal ischemia. J Exp Med. 1934;59:347-379.

5. Berenguer LM, Garcia-Estan J, Ubeda M, Ortiz AJ, Quesada T. Role of renin-angiotensin system in the impairment of baroreflex control of heart rate in renal hypertension. J Hypertens. 1991;9:1127-1133.

6. Tsyrlin VA, Galagudza MM, Kuzmenko NV, Pliss MG, Rubanova NS, Shcherbin YI. Arterial baroreceptor reflex counteracts long-term blood pressure increase in the rat model of renovascular hypertension. PLoS ONE. 2013;8:e64788.

7. Oliveira-Sales EB, Toward MA, Campos RR, Paton JFR. Revealing the role of the autonomic nervous system in the development and maintenance of Goldblatt hypertension in rats. Auton Neurosci. 2014;183:23-29.

8. Oliveira-Sales EB, Nishi EE, Carillo BA, Boim MA, Dolnikoff MS, Bergamaschi CT, Campos RR. Oxidative stress in the sympathetic premotor neurons contributes to sympathetic activation in renovascular hypertension. Am J Hypertens. 2009;22:484-492.

9. Navar LG, Zou L, Von Thun A, Tarng Wang C, Imig JD, Mitchell KD. Unraveling the Mystery of Goldblatt Hypertension. Physiology. 1998;13:170-176.

10. Martinez-Maldonado M. Pathophysiology of renovascular hypertension. Hypertension. 1991;17:707-719.

11. Marson O, Saragoca MA, Ribeiro AB, Bossolan D, Tufik S, Ramos OL. Anteroventral third ventricle and renin-angiotensin system interaction in the two-kidney, one clip hypertensive rat. Hypertension. 1983;5:V90-V93.

12. Matsumura K, Averill DB, Ferrario CM. Angiotensin II acts at AT1receptors in the nucleus of the solitary tract to attenuate the baroreceptor reflex. Am J Physiol. 1998;275:R1611-R1619.

13. Toney GM, Porter JP. Effects of blockade of AT1 and AT2 receptors in brain on the central angiotensin II pressor response in conscious spontaneously hypertensive rats. Neuropharmacology. 1993;32:581-589.

14. Michelini LC, Bonagamba LG. Angiotensin II as a modulator of baroreceptor reflexes in the brain stem of conscious rats. Hypertension. 1990;15:I45-I50. 
15. Sato MA, Colombari E, Morrison SF. Inhibition of neurons in commissural nucleus of solitary tract reduces sympathetic nerve activity in SHR. Am J Physiol Heart Circ Physiol. 2002;282:H1679-H1684.

16. Freiria-Oliveira AH, Blanch GT, Li H, Colombari E, Colombari DSA, Sumners C. Macrophage migration inhibitory factor in the nucleus of solitary tract decreases blood pressure in SHRs. Cardiovasc Res. 2013;97:153-160.

17. Gallinat S, Busche S, Raizada MK, Sumners C. The angiotensin II type 2 receptor: an enigma with multiple variations. Am J Physiol. 2000;278:E357-E374.

18. Ichiki T, Labosky PA, Shiota C, Okuyama S, Imagawa Y, Fogo A, Niimura F, Ichikawa I, Hogan BL, Inagami T. Effects on blood pressure and exploratory behavior of mice lacking angiotensin II type-2 receptor. Nature. 1995;377:748-750.

19. Gross V, Milia AF, Plehm R, Inagami T, Luft FC. Long-term blood pressure telemetry in AT2 receptor-disrupted mice. J Hypertens. 2000;18: 955-961.

20. Bosnyak S, Welungoda IK, Hallberg A, Alterman M, Widdop RE, Jones ES. Stimulation of angiotensin AT2 receptors by the nonpeptide agonist, Compound 21, evokes vasodepressor effects in conscious spontaneously hypertensive rats. Br J Pharmacol. 2010;159:709-716.

21. Kang J, Sumners C, Posner P. Modulation of net outward current in cultured neurons by angiotensin II: involvement of AT1 and AT2 receptors. Brain Res. 1992;580:317-324.

22. Dampney RAL. Functional organization of central pathways regulating the cardiovascular system. Physiol Rev. 1994;74:323-364.

23. Santos RAS, Ferreira AJ, Verano-Braga T, Bader M. Angiotensinconverting enzyme 2, angiotensin-(1-7) and Mas: new players of the renin-angiotensin system. J Endocrinol. 2013;216:R1-R17.

24. Ali Q, Wu Y, Hussain T. Chronic AT2 receptor activation increases renal ACE2 activity, attenuates AT1 receptor function and blood pressure in obese Zucker rats. Kidney Int. 2013;84:931-939.

25. Sriramula S, Cardinale JP, Lazartigues E, Francis J. ACE2 overexpression in the paraventricular nucleus attenuates angiotensin II-induced hypertension. Cardiovasc Res. 2011;92:401-408.

26. Xiao L, Gao L, Lazartigues E, Zucker IH. Brain-Selective overexpression of angiotensin-converting enzyme 2 attenuates sympathetic nerve activity and enhances baroreflex function in chronic heart failure. Hypertension. 2011;58:1057-1065.

27. Smith SH, Bishop SP. Selection criteria for drug-treated animals in twokidney, one clip renal hypertension. Hypertension. 1986;8:700-705.
28. Cervenka L, Horacek V, Vaneckova I, Hubacek JA, Oliverio MI, Coffman TM, Navar LG. Essential role of AT1A receptor in the development of 2K1C hypertension. Hypertension. 2002;40:735-741.

29. Morishita R, Higaki J, Nakamura Y, Aoki M, Yamada K, Moriguchi A, Rakugi H, Tomita N, Tomita S, Yu H,. Effect of an antihypertensive drug on brain angiotensin II levels in renal and spontaneously hypertensive rats. Clin Exp Pharmacol Physiol. 1995;22:665-669.

30. Chen AD, Zhang SJ, Yuan N, Xu Y, De W, Gao XY, Zhu GQ. Angiotensin AT1 receptors in paraventricular nucleus contribute to sympathetic activation and enhanced cardiac sympathetic afferent reflex in renovascular hypertensive rats. Exp Physiol. 2011;96:94-103.

31. Lenkei Z, Palkovits M, Corvol P, Llorens-Cortes C. Expression of angiotensin type-1 (AT1) and type-2 (AT2) receptor mRNAs in the adult rat brain: a functional neuroanatomical review. Front Neuroendocrinol. 1997; 18:383-439.

32. Gao J, Zhang H, Le KD, Chao J, Gao L. Activation of central angiotensin type 2 receptors suppresses norepinephrine excretion and blood pressure in conscious rats. Am J Hypertens. 2011;24:724-730.

33. Gao L, Wang W, Wang W, Li H, Sumners C, Zucker IH. Effects of angiotensin type 2 receptor overexpression in the rostral ventrolateral medulla on blood pressure and urine excretion in normal rats. Hypertension. 2008;51:521-527.

34. Lohmeier TE, Irwin ED, Rossing MA, Serdar DJ, Kieval RS. Prolonged activation of the baroreflex produces sustained hypotension. Hypertension. 2004;43:306-311.

35. Fraga-Silva RA, Ferreira AJ, Dos Santos RA. Opportunities for targeting the angiotensin-converting enzyme 2/angiotensin-(1-7)/Mas receptor pathway in hypertension. Curr Hypertens Rep. 2013;15:31-38.

36. Sakima A, Averill DB, Gallagher PE, Kasper SO, Tommasi EN, Ferrario CM, Diz DI. Impaired heart rate baroreflex in older rats: role of endogenous angiotensin-(1-7) at the nucleus tractus solitarii. Hypertension. 2005;46:333-340.

37. Chaves GZ, Caligiorne SM, Santos RA, Khosla MC, Campagnole-Santos MJ. Modulation of the baroreflex control of heart rate by angiotensin-(1-7) at the nucleus tractus solitarii of normotensive and spontaneously hypertensive rats. J Hypertens. 2000;18:1841-1848.

38. Diz DI, Garcia-Espinosa MA, Gegick S, Tommasi EN, Ferrario CM, Ann Tallant E, Chappell MC, Gallagher PE. Injections of angiotensin-converting enzyme 2 inhibitor MLN4760 into nucleus tractus solitarii reduce baroreceptor reflex sensitivity for heart rate control in rats. Exp Physiol. 2008;93:694-700.

\section{Novelty and Significance}

\section{What Is New?}

- Increased expression of angiotensin type 2 receptors (AT2R) in the nucleus of the solitary tract/dorsal motor nucleus of vagus attenuated the development 2-kidney 1-clip (2K1C) hypertension.

- Increased AT2R expression in the nucleus of the solitary tract/dorsal motor nucleus of vagus of $2 \mathrm{~K} 1 \mathrm{C}$ rats also restored baroreflex function and sympathetic modulation of arterial pressure to normal in $2 \mathrm{~K} 1 \mathrm{C}$ rats.

- These beneficial effects of AT2R in $2 \mathrm{~K} 1 \mathrm{C}$ rats are associated with increased expression of angiotensin-converting enzyme 2 mRNA at the nucleus of the solitary tract/dorsal motor nucleus of vagus.

\section{What Is Relevant?}

- AT2R exerts opposite effects when compared with angiotensin II via its AT1R.
- Increasing AT2R levels in the nucleus of the solitary tract/dorsal motor nucleus of vagus may be a mechanism that can be targeted as a potential antihypertensive strategy.

\section{Summary}

Increased expression of AT2R within the solitary-vagal complex of $2 \mathrm{~K} 1 \mathrm{C}$ rats impairs the full development of hypertension in these animals and restores the baroreflex function and the sympathetic modulation of the systolic blood pressure to normal values. The normalization of angiotensin-converting enzyme 2 mRNA levels in the solitary-vagal complex after AT2R overexpression might be an important mechanism for these beneficial effects of AT2R. 


\title{
Increased Expression of Angiotensin II Type 2 Receptors in the Solitary-Vagal Complex Blunts Renovascular Hypertension
}

Graziela Torres Blanch, André Henrique Freiria-Oliveira, Guilherme Fleury Fina Speretta, Eduardo J. Carrera, Hongwei Li, Robert C. Speth, Eduardo Colombari, Colin Sumners and Débora S.A. Colombari

\author{
Hypertension. 2014;64:777-783; originally published online June 23, 2014; \\ doi: 10.1161/HYPERTENSIONAHA.114.03188 \\ Hypertension is published by the American Heart Association, 7272 Greenville Avenue, Dallas, TX 75231 \\ Copyright (C) 2014 American Heart Association, Inc. All rights reserved.
}

Print ISSN: 0194-911X. Online ISSN: 1524-4563

The online version of this article, along with updated information and services, is located on the World Wide Web at:

http://hyper.ahajournals.org/content/64/4/777

Data Supplement (unedited) at:

http://hyper.ahajournals.org/content/suppl/2014/06/23/HYPERTENSIONAHA.114.03188.DC1

\footnotetext{
Permissions: Requests for permissions to reproduce figures, tables, or portions of articles originally published in Hypertension can be obtained via RightsLink, a service of the Copyright Clearance Center, not the Editorial Office. Once the online version of the published article for which permission is being requested is located, click Request Permissions in the middle column of the Web page under Services. Further information about this process is available in the Permissions and Rights Question and Answer document.
}

Reprints: Information about reprints can be found online at: http://www.lww.com/reprints

Subscriptions: Information about subscribing to Hypertension is online at: http://hyper.ahajournals.org//subscriptions/ 


\section{INCREASED EXPRESSION OF AT2 RECEPTORS IN THE SOLITARY- VAGAL COMPLEX BLUNTS RENOVASCULAR HYPERTENSION}

Graziela Torres Blanch ${ }^{1}$, André Henrique Freiria-Oliveira ${ }^{1}$, Guilherme Fina Fleury Speretta $^{1}$, Eduardo J Carrera ${ }^{2}$, Hongwei Li $^{3}$, Robert C. Speth ${ }^{2}$, Eduardo Colombari ${ }^{1}$, Colin Sumners $^{4^{*}}$, Débora S. A. Colombari ${ }^{1^{*}}$

${ }^{1}$ Department of Physiology and Pathology, School of Dentistry, São Paulo State University, Araraquara, SP, Brazil; ${ }^{2}$ Department of Pharmaceutical Sciences, College of Pharmacy, Nova Southeastern University, Fort Lauderdale, FL, USA; ${ }^{3}$ School of Biotechnology, Southern Medical University, Guangzhou, China; ${ }^{4}$ Department of Physiology and Functional Genomics and McKnight Brain Institute, College of Medicine, University of Florida, Gainesville, FL, USA.

Short title: NTS/DMV AT2R and blood pressure in 2K1C rats

*C. Sumners and D. S. A. Colombari are co-senior authors

Corresponding author:

Débora Simões Almeida Colombari, Ph.D.

Departamento de Fisiologia e Patologia -

Faculdade de Odontologia de Araraquara-UNESP

Rua Humaitá, 1680, Araraquara, 14801-903, SP, Brazil

Phone: +55 (16) 3301-6483

Fax: + 55 (16) 33016488

E-mail: deborac@foar.unesp.br

or

Colin Sumners, Ph.D.

Department of Physiology and Functional Genomics

College of Medicine, University of Florida

1600 Southwest Archer Road, Gainesville, FL, 32610, USA

PO-BOX: 100274

Phone: +1 (352) 3924485

FAX: +1 (352) 2940191

E-mail: csumners@ufl.edu 


\section{Methods}

\section{Animals}

Male Holtzman rats and male Sprague Dawley (SD) rats (150 - 180 g) were used for these experiments. Rats were kept on a 12-hour light/dark cycle in climate-controlled rooms. Rat chow and water were provided ad libitum. The Ethics Committee for Animal Care and Use (CEUA) of the School of Dentistry of Araraquara, São Paulo State University approved all experimental protocols used for Holtzman rats (Proc. CEUA 07/2011), and the University of Florida Institutional Animal Care and Use Committee approved all experimental protocols with the SD rats. In addition, the principles governing the care and treatment of animals, as stated in the Guide for the Care and Use of Laboratory Animals published by the US National Institutes of Health (eighth edition, 2011) and adopted by the American Physiological Society, were followed at all times during this study.

\section{Renovascular hypertension model and implantation of telemetry transmitters}

Male Holtzman rats were anesthetized with ketamine $[80 \mathrm{mg} / \mathrm{kg}$ of body weight (b. wt.)] combined with xylazine ( $7 \mathrm{mg} / \mathrm{kg}$ of b. wt.), and underwent two surgeries. First, the left renal artery was partially obstructed using a silver clip of $0.2 \mathrm{~mm}$ width. This occlusion significantly reduces renal blood flow and elicits hypertension. ${ }^{1}$

Normotensive animals were submitted to the same surgical procedure without partial renal artery occlusion (sham surgery). We will refer Holtzman rats with sham surgery as normotensive (NT) rats. Immediately following implantation of the silver clip or sham surgery, rats were implanted with telemetry transducers (Data Sciences International; TA11PAC40) in the abdominal aorta as described previously, to record arterial pressure and heart rate. ${ }^{2,3}$ Following the surgeries animals received a prophylactic dose of penicillin (50,000 IU, intramuscularly) and a dose of the anti-inflammatory ketoprofen ( $1 \mathrm{mg} / \mathrm{kg}$ of b.w, subcutaneously).

\section{In vivo gene transfer in the solitary-vagal complex}

Holtzman rats were anesthetized with ketamine and xylazine as described above and placed in a stereotaxic frame (David Kopf Instruments, Tujunga, CA). A partial craniotomy of the occipital bone was performed, and the dorsal surface of the brainstem was exposed. AAV2-CBA-eGFP or AAV2-CBA-AT2R were microinjected at 5 different sites along the solitary-vagal complex (comprised of the NTS and DMV or NTS/DMV). Each microinjection consisted of $150 \mathrm{~nL}$ vector/site (eGFP, $1.5 \times 10^{12}$ genome copies and AT2R, $3.6 \times 10^{11}$ genome copies [ $\left.\mathrm{gc}\right] /$ injection) and was performed as follows: at the level of the calamus scripitorius and $0.5 \mathrm{~mm}$ rostral and $0.4 \mathrm{~mm}$ caudal to it; $0.2-0.5 \mathrm{~mm}$ lateral from the midline and $0.4 \mathrm{~mm}$ ventral to the dorsal surface of the medulla . Each injection was made over a period of $1 \mathrm{~min}$. A prophylactic dose of penicillin (50,000 IU, intramuscularly) and of the anti-inflammatory ketoprofen (1 mg/kg of b.wt, subcutaneously) were given post surgically. Identical microinjections of AAV2-CBA-eGFP or AAV2-CBA-AT2R were made in SD rats, the only differences being that anesthesia was induced using $100 \% \mathrm{O}_{2} / 4 \%$ isoflurane, and was maintained throughout the surgeries by the administration of $100 \% \mathrm{O}_{2} / 2 \%$ isoflurane, and that buprenorphine $(0.05 \mathrm{mg} / \mathrm{kg}$, s.c., Hospira Inc., Lake Forest, IL, USA) was administered to rats immediately following the survival surgeries. During the surgeries/procedures, the level of anesthesia was monitored by checking the eye blink reflex and a reaction to paw pinch, and was adjusted if necessary. AAV2-CBA-eGFP or AAV2-CBA-AT2R 
were constructed as described previously, ${ }^{4,5}$ and these vectors elicit gene transduction primarily in neurons of all different phenotypes. ${ }^{6}$

\section{Baroreflex Function}

On the day before the experiment, rats were anesthetized with ketamine and xylazine as described above, and a polyethylene tube (PE-10 connected to a PE-50) was inserted into the abdominal aorta through the femoral artery and another catheter was implanted into the femoral vein. Arterial and venous catheters were tunneled subcutaneously and exposed on the back of the rat. To record pulsatile arterial pressure, MAP and HR in conscious unrestrained, freely moving animals, the arterial catheter was connected to a Statham Gould (P23 Db; El Segundo, CA, USA) pressure transducer coupled to a preamplifier (model ETH-200 Bridge Bio Amplifier, Chicago, IL, USA) that was connected to a Powerlab computer data acquisition system (model Powerlab 16SP, ADInstruments, Colorado Springs CO, USA). After a baseline period of cardiovascular recordings, rats received iv injections of phenylephrine $(5 \mu \mathrm{g} / \mathrm{kg}$, b.wt.) or sodium nitroprusside (SNP; $30 \mu \mathrm{g} / \mathrm{kg}$, b.wt.) to test the HR reflex responses to pressor and depressor stimuli, respectively. We analyzed the one second mean HR values in response to $10 \mathrm{mmHg}$ incremental changes in MAP, starting in $5 \mathrm{mmHg}$ up to a maximal change of $35 \mathrm{mmHg}$. The values were plotted, a linear regression was performed for each animal, and the slope of each linear regression was used to calculate the differences between groups.

\section{Euthanasia}

Rats were euthanized by placing them under deep anesthesia with either isoflurane ( $5 \%$ in $\left.100 \% \mathrm{O}_{2}\right)$ or sodium thiopental $(70 \mathrm{mg} / \mathrm{kg}$ of $\mathrm{b}$. wt, ip), followed by either decapitation or transcardial perfusion with chilled $0.9 \%$ saline followed by $4 \%$ paraformaldehyde, depending on the protocol.

\section{eGFP fluorescence in the NTS}

Animals were perfused transcardially, brainstems were removed, frozen and cut in coronal sections (30- $\mu \mathrm{m}$ thickness) on a cryostat (Leica, CM1850 UV, Wetzlar, Hesse, Germany). The sections were visualized using a Leica fluorescence microscope (Leica, DM5500 B, Wetzlar, Hesse, Germany) with the appropriate filter to visualize the eGFP expression. We used the area postrema (AP) and central canal as anatomical landmarks to define the rostro-caudal and dorso-ventral levels of the NTS/DMV; the intermediate NTS (iNTS) is located at AP level and commissural NTS (cNTS) is located caudal to the AP. The NTS/DMV complex is dorsal to the central canal.

\section{Kidney analysis}

At the end of the experiments, rats were weighed and under deep anesthesia as described above, the kidneys were removed and weighed to confirm atrophy in the clipped kidney and hypertrophy in the contralateral kidney. ${ }^{7}$ After kidney removal, some animals were decapitated for brain microdissection (see below).

\section{qRT-PCR analyses in the NTS/DMV}

Animals were decapitated, the brains were removed and the NTS was collected by micropunch with the aid of a surgical microscope using the obex as a reference site. AT2R, AT1R and ACE2 mRNA levels within the NTS were analyzed by qRT-PCR as 
detailed previously ${ }^{2}$ and were expressed using the $\Delta \mathrm{CT}$ method normalized to $18 \mathrm{~S}$ mRNA levels.

\section{AT2R autoradiography in the NTS/DMV}

Animals were perfused transcardially with chilled phosphate buffered saline. The brains were removed quickly, wrapped in aluminum foil, and frozen at $-80{ }^{\circ} \mathrm{C}$ until sectioned. Coronal sections $(20-\mu \mathrm{m}$ thickness) were cut from rat brains using a cryostat (Leica, CM1850 UV, Wetzlar, Hesse, Germany) and thaw-mounted onto gelatin-coated slides. The sections were allowed to dry at room temperature and then stored at $-80^{\circ} \mathrm{C}$ until the time of autoradiography. The frozen sections were thawed and in vitro receptor autoradiography was performed using an established protocol. ${ }^{8}$ Briefly, brain sections

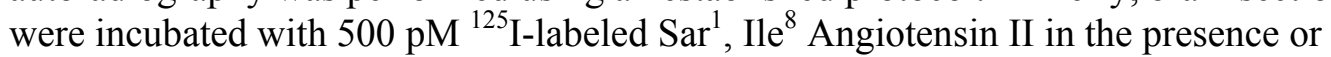
absence of $10 \mu \mathrm{M}$ PD123319 to block $\mathrm{AT}_{2}$ receptors, $10 \mu \mathrm{M}$ losartan to block $\mathrm{AT}_{1}$ receptors, or $3 \mu \mathrm{M}$ Angiotensin II to establish non-specific binding. X-ray films exposed to ${ }^{125}$ I-labeled sections were scanned and analyzed using MCID (Interfocus Imaging Ltd.). Brain regions of interest were manually circumscribed using the rat brain atlas of Paxinos and Watson, $7^{\text {th }}$ edition (2014) as a guide. MCID automatically calculated average relative optical density values of circumscribed areas. Specific binding to the $\mathrm{AT}_{1}$ or $\mathrm{AT}_{2}$ receptors was defined as the difference between nonspecific binding and binding in the presence of PD123319 or losartan, respectively.

\section{Cardiovascular variability analysis}

The pulse interval (PI) and systolic arterial pressure (SAP) variability analyses were performed using a custom computer software (CardioSeries v2.4 -

http://www.danielpenteado.com), as described previously. ${ }^{9-11}$ Brifely, beat-by-beat series obtained from pulsatile arterial pressure recordings were converted to data points every $100 \mathrm{~ms}$ using cubic spline interpolation $(10 \mathrm{~Hz})$. The interpolated series was divided into half-overlapping sequential sets of 512 data points $(51.2 \mathrm{~s})$. Before calculation of the spectral power density, segments were visually inspected and nonstationary data were not taken into consideration. A Hanning window was used to attenuate side effects and the spectrum was computed using a direct FFT algorithm for discrete time series. The spectra were integrated in low-frequency (LF; $0.2-0.75 \mathrm{~Hz}$ ) and high-frequency (HF; $0.75-3 \mathrm{~Hz}$ ) bands, and results are expressed in absolute for SAP (mmHg2) and normalized units $(\mathrm{nu})$ for PI. The normalized values were achieved by calculating the percentage of LF and HF power with regard to the total power of spectrum minus very low frequency band (VLF; $<0.2 \mathrm{~Hz}$ ) power. ${ }^{12,13}$ To assess the sympathovagal balance, $\mathrm{LF} / \mathrm{HF}$ ratio of PI variability was calculated. ${ }^{14}$

\section{Data analysis}

All data are expressed as means \pm SEM. Different statistical tests were applied for group comparisons depending on the experimental design. One or two-way ANOVA was used and both were followed by Sidak's multiple comparisons (for autoradiography data) or Student Newman-Keuls (for all other experiments) post hoc tests to compare individual means. In all tests differences were considered significant at $p<0.05$. 


\section{References}

1. Ploth DW, Roy RN, Huang WC, Navar LG. Impaired renal blood flow and cortical pressure autoregulation in contralateral kidneys of Goldblatt hypertensive rats. Hypertension. 1981; 3:67-74.

2. Li H, Gao Y, Freire CD, Raizada MK, Toney GM, Sumners C. Macrophage migration inhibitory factor in the PVN attenuates the central pressor and dipsogenic actions of angiotensin II. FASEB J. 2006; 20:1748-1750.

3. Freiria-Oliveira AH, Blanch GT, Li H, Colombari E, Colombari DSA, Sumners C. Macrophage migration inhibitory factor in the nucleus of solitary tract decreases blood pressure in SHRs. Cardiovasc Res. 2013; 97:153-160.

4. Li HW, Gao YX, Raizada MK, Sumners C. Intronic enhancement of angiotensin II type 2 receptor transgene expression in vitro and in vivo. Biochem Biophys Res Commun. 2005; 336:29-35.

5. Li HW, Gao YX, Matsuura T, Martynyuk A, Raizada MK, Sumners C. Adenoviral-mediated neuron specific transduction of angiotensin II type 2 receptors. Regul Pept. 2005; 126:213-222.

6. Zhang Y, Gao Y, Speth RC, Jiang N, Mao Y, Sumners C, Li H. Adenoviral and adeno-associated viral vectors-mediated neuronal gene transfer to cardiovascular control regions of the rat brain. Int J Med Sci. 2013; 10:607-616.

7. Smith SH, Bishop SP. Selection criteria for drug-treated animals in two-kidney, one clip renal hypertension. Hypertension. 1986; 8:700-705.

8. Speth RC, Barry WT, Smith MS, Grove KL. A comparison of brain angiotensin II receptors during lactation and diestrus of the estrous cycle in the rat. American Journal of Physiology - Regulatory, Integrative and Comparative Physiology. 1999; 277:R904-R909.

9. Tezini GCSV, Dias DPM, Souza HCD. Aerobic physical training has little effect on cardiovascular autonomic control in aging rats subjected to early menopause. Experimental Gerontology. 2013; 48:147-153.

10. Pires W, Wanner SP, Lima MR, Fonseca IA, Fumega U, Haibara AS, Coimbra $\mathrm{CC}$, Lima NR. Physical exercise performance in temperate and warm environments is decreased by an impaired arterial baroreflex. PLoS One. 2013; 8:e72005.

11. Sabino JP, da Silva CA, de Melo RF, Fazan R, Jr., Salgado HC. The treatment with pyridostigmine improves the cardiocirculatory function in rats with chronic heart failure. Auton Neurosci. 2013; 173:58-64.

12. Billman GE. Heart rate variability - a historical perspective. Front Physiol. 2011; 2:86.

13. van de Borne P, Montano N, Pagani M, Oren R, Somers VK. Absence of lowfrequency variability of sympathetic nerve activity in severe heart failure. Circulation. 1997; 95:1449-1454.

14. Montano N, Ruscone TG, Porta A, Lombardi F, Pagani M, Malliani A. Power spectrum analysis of heart rate variability to assess the changes in sympathovagal balance during graded orthostatic tilt. Circulation. 1994; 90:1826-1831. 

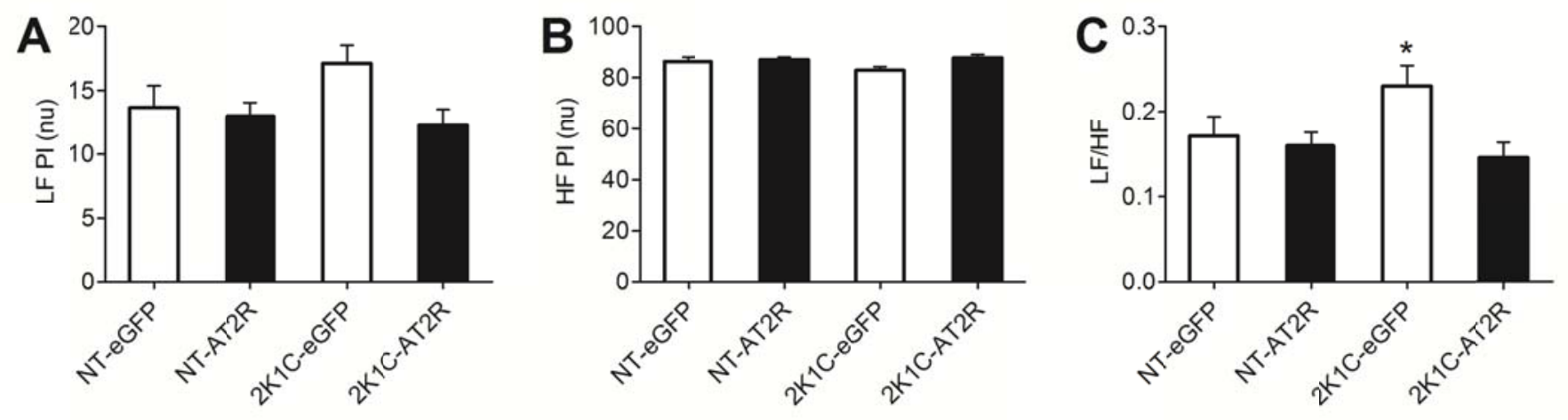

Figure S1: Normotensive (NT) or 2K1C rats received intra-NTS/DMV injections of AAV2-CBA-eGFP or AAV2-CBA-AT2R followed by analysis of the PI variability. Power of the low and high frequency bands (LF, panel A; HF, panel B) of pulse interval (PI), and $\mathrm{LF} / \mathrm{HF}$ ratio (panel $\mathrm{C}$ ). ${ }^{*} \mathrm{p}<0.05$ vs. all groups. 